\title{
Deep Dive into Digital Transformation in Higher Education Institutions
}

\author{
Mamdouh Alenezi $\mathbb{D}$
}

check for updates

Citation: Alenezi, M. Deep Dive into Digital Transformation in Higher Education Institutions. Educ. Sci. 2021, 11, 770. https://doi.org/ 10.3390/educsci11120770

Academic Editor: Mike Joy

Received: 30 October 2021

Accepted: 25 November 2021

Published: 29 November 2021

Publisher's Note: MDPI stays neutral with regard to jurisdictional claims in published maps and institutional affiliations.

Copyright: (C) 2021 by the author. Licensee MDPI, Basel, Switzerland. This article is an open access article distributed under the terms and conditions of the Creative Commons Attribution (CC BY) license (https:/ / creativecommons.org/licenses/by/ $4.0 /)$.
College of Computer and Information Sciences, Prince Sultan University, Riyadh 11586, Saudi Arabia; malenezi@psu.edu.sa

\begin{abstract}
In the present times, digital transformation has gained momentum. Contemporary higher education institutions have been embracing new technologies and transforming their practices, business models and process. Digital transformation in the higher education institutions is about the development of new more advanced and effective methods and practices in pursuit of the higher education's mission. The present paper links digital transformation and higher education institutions. The paper discusses existing models for the incorporation of digital transformation in higher education institutions. The paper also delineates the challenges faced by higher education institutions in pursuit of digital transformation.
\end{abstract}

Keywords: digital transformation; educational organization; maturity model; technology adoption

\section{Introduction}

In the recent decade, digital transformation has gained momentum. In the present times, digital transformation is viewed as an evolutionary process influencing all the aspects and dimensions of life involving both people and organizations. The review of the existing literature reveals a wide range of views on digital transformation resulting in a range of interpretations and conceptualizations. According to some authors, digital transformation is merely about the establishment of the application of IT in business practices and operations [1]. While practitioners and scholars have presented digital transformation as a process involving dramatic and disruptive changes and outcomes that lead to disruption in the business environment, digital transformation can be seen as an evolutionary process [2]. In this context, one of the most holistic and balanced conceptualizations characterizes digital transformations as an evolutionary process that leverages digital technologies and capabilities resulting in value-generating business models, more advanced and efficient business practices and operations and improved service delivery [3].

Digital transformation can also be seen from the perspective of the link between the structural, strategic and technological changes that are imperative to meet the demands of the contemporary digital era [4] that emphasizes the need to align the old and new practices and systems of the organisation. Due to the incorporation of the new technologies, digital transformation entails innovation focused on the transformation of organisational products and processes and resolution of the existing and potential challenges. This also entails continuous interaction between the organisational members and the digital technologies aligning the business practices, services and the business model [5].

In the present era characterised by age of revolutionized knowledge, it has become imperative and critical to comprehend the values of technological initiatives and their role in the transformation of the business models. A number of sectors have been fundamentally reformed with the introduction of technology-oriented value-added processes and practices. As we progress further into the fourth industrial revolution, more disruptive digital technologies will have a greater influence on the development of creative, flexible business models. A number of buzzwords have been emerged to characterise this trend such as e-readiness, IT maturity etc. [6]. 
For centuries, higher education institutions have been the epicentre of knowledge creation and diffusion. However, in the present times, access to information and knowledge is no longer limited to the physical space of the educational institutes. Rather, information and knowledge pertinent to a wide variety of subjects can be gained from various platforms, open-source databases and web browsers, applications, encyclopaedias which enable the users to add to their learning. This emerging trend, although poses various challenges, must be seen as an opportunity rather than a threat to the higher education institutions [7].

Contemporary higher education institutions have been embracing new technologies and transforming their practices, business models and process. Digital transformation in the higher education institutions concerns the development of new more advanced and effective methods and practices in pursuit of the higher education's mission. A number of studies have also claimed that digital transformation is not merely about the incorporation of technology in business processes. Rather, digital transformation is a process for analyzing the needs and the demands of the stakeholders and ensuring the provision of education and research services that are in line with the knowledge needs of the students. Digital transformation is being gradually implemented in educational institutes across the world ensuring that the learning of the students is supported by digital tools [8].

In the context of the contemporary knowledge society, the digital transformation must be considered as a critical process in which the production of knowledge and the processing of information take place through information technologies such as virtual reality, online learning video integration, gamification, and big data [9]. Moreover, the success in this digital age is determined by the ability of the institutions to create and appropriately capture the information such as student engagement, outcomes attainment, satisfaction, etc. [10]. Concerns have grown regarding how education manages its position in the knowledge society. Higher education institutions are faced with significant challenges pertinent to the digital transformation not only in terms of the adoption of the digital tools and technology in the teaching and learning process but also for the incorporation of the technologies for changing and modifying the existing systems, processes, communication modes and channels and all the other academic and administrative activities involved in the institute.

A number of digital tools and technologies have been developed to meet the changing educational needs of the students. Virtual educational platforms around the world have been established with a wide variety of new simulative methods of learning. However, higher education institutions still has a lot to do to achieve the digital transformation that this era requires. It is imperative to consider digital transformation at a macro level considering all the areas where there is a need for the adoption of digital technology in order to innovate and improve the service delivery and education system of the educational institutes. In order to meet the international standards, it is imperative to adhere to such policies and standards, which demonstrate the reputation of the higher education institutes supporting the students with the advanced learning mechanism and knowledge delivery that are tailored to the curriculum. The present paper provides an overview of literature pertinent to the digital transformation of higher educational institutes through a comprehensive review of the relevant literature. The paper highlights the digital maturity as well as the challenges, opportunities and awareness of the digital transformation in educational institutes.

\section{Digital Transformation Background}

In the present times, digital transformation has been emerging as one of the top priorities of educational institutes, particularly, higher education institutions. Similar to business institutions, it is an essential process for achieving a competitive edge in the industry. A number of authors have attempted to conceptualize the notion of digital transformation. Among them, Hess et al. [11] have conceptualized the notion as change brought about by digital technology for improving overall performance and productivity. This aligns with the definition by [12] that stated that with the incorporation of the digital 
transformation, the organization's processes, practices, procedures, competencies, systems and models of an organization are transformed in a strategic and prioritized manner to take full advantage of technological advancements, as well as its increased social effect. In this context, similar to any other industry, if the higher education institutions want to stay relevant to the changing industry scenarios and trends and to remain a significant component of this transition throughout time and not fade away from the scene, they must grow holistically [13].

Several research studies proposed and discussed new skill sets that are needed in the next decade [14]. These skills are not limited to technical skills like programming. Rather they include skills and competencies in terms of creative thinking, problem-solving, agile working, cognitive abilities, critical thinking, cross-cultural competencies etc. Thus, these skills or competencies are not limited to any particular technology.

In the context of digital transformation, it is important to note that the terms digitization, digitalization and digital transformation have been used synonymously and interchangeably. However, they all relate to different conceptualizations. Digitization refers to modifying analog tools into digital representations. Digitalization refers to improvements with the incorporation of digital data. On the other hand, digital transformation refers to disruptive and holistic changes in the organisation with the incorporation of digital technologies. Digital abilities and competencies required for successful digital transformation are not really relevant to digitization and digitalization. They are more concerned with the two primary capacities of abstraction and contextualization.

The major question is how do digital skills and transformation affect higher education? Digital learning can be seen as an opportunity for higher education to enhance their pedagogical approaches. E-learning was originally opted to increase the quality of learning by using online tools and simplifying access to information, as well as distant exchanges and cooperation [15]. However, most individuals only associate e-learning with digitization and digitalization. It is more appropriate to consider e-Learning as a catch-all term for any form of learning that relies on or benefits from electronic communication and cutting-edge technology [16].

The use of terms such as digital learning and digitally transformed learning allows for discussion of teaching and learning processes emphasizing common practices. Scalable customized learning is possible with digitally transformed learning. In this sense, digital approaches to higher education might expand beyond the use of technology gadgets and toward new learning experiences made possible by technological advancements. The focus would not be on technology, and the term "digital" might potentially open up possibilities for rethinking teaching and learning approaches.

\section{Digital Maturity Models}

Maturity models are well-known methods in the literature to measure the maturity of organizations $[17,18]$. Digital maturity can be defined as the state of digital transformation in an organization [19]. Applying these concepts to educational higher education organizations is unfortunately rare. Current models are restricted to information systems management in these organizations and are still yet to grow [20]. Maturity models are composed of different components such as maturity level, a descriptor for each maturity level, dimensions, best practices or elements associated with the corresponding dimensions, and a description of each element for each maturity level [18]. De Bruin et al. [21] classified maturity models into three different types: descriptive, prescriptive, or comparative. The descriptive models assist in the assessment of the given situation, the prescriptive models are appropriate for implementing a plan or initiative and the comparative models are suitable comparisons and benchmarking.

Consultancy companies are considered as appropriate advisors to provide consultations with regard to digital maturity models. Since there is a large number of management consulting firms, the present paper only discusses the maturity models of the top firms in the industry, assuming that their models are the most common in practice. It is found that 
the consulting firms only provide generic MMs publicly. This may be because of the fact that such consulting firms consider their mature models to be intellectual property and thus, have kept them as confidential data. Table 1 summarizes these digital maturity models.

Table 1. Overview of Consultancy Companies Digital Maturity Models.

\begin{tabular}{|c|c|c|c|}
\hline \# & $\begin{array}{l}\text { Consulting } \\
\text { Company }\end{array}$ & Digital Maturity Model & Dimensions \\
\hline 1 & Accenture & Digital Capability Assessment (DCA) & $\begin{array}{l}\text { - Strategy and Leadership } \\
\text { - People and Culture } \\
\text { - Product and Service } \\
\text { - Customer Experience } \\
\text { - Enterprise Enablement }\end{array}$ \\
\hline 2 & BCG & Digital Acceleration Index (DAI) & $\begin{array}{l}\text { - Business strategy driven by digital } \\
\text { - Digitize the core } \\
\text { - New digital growth } \\
\text { - Enablers }\end{array}$ \\
\hline 3 & Deloitte & Digital Maturity Model (DMM) & $\begin{array}{l}\text { - } \text { Customer } \\
\text { - Strategy } \\
\text { - Technology } \\
\text { - Operations } \\
\text { - Organization and Culture }\end{array}$ \\
\hline 4 & EY & Digital Readiness Assessment & $\begin{array}{l}\text { - Strategy, Innovation and Growth } \\
\text { - Customer Experience } \\
\text { - Supply Chain and Operations } \\
\text { - Technology } \\
\text { - Risk and Cybersecurity } \\
\text { - Finance, Legal and Tax } \\
\text { - People and Organization }\end{array}$ \\
\hline 5 & KPMG & Digital Readiness Assessment (DRA) & $\begin{array}{l}\text { - Development and Purchasing } \\
\text { - Production } \\
\text { - Marketing } \\
\text { - Sales }\end{array}$ \\
\hline 6 & McKinsey & Digital Capabilities (DC) & $\begin{array}{l}\text { - Data-driven Insights } \\
\text { - Integrated Customer Experience } \\
\text { - Digital Marketing } \\
\text { - Digitally-enabled Operations } \\
\text { - Next-gen Technology } \\
\text { - Digital Enablers }\end{array}$ \\
\hline 7 & PWC & Maturity Assessment & $\begin{array}{l}\text { - Digital business models and customer access } \\
\text { - Digitization of products and service offerings } \\
\text { - Digitization and integration of vertical and horizontal value chains } \\
\text { - Data and analytics as core capability } \\
\text { - Agile IT architecture } \\
\text { - Compliance, security, legal, and tax } \\
\text { - Organization, employees, and digital culture }\end{array}$ \\
\hline
\end{tabular}

\section{Digital Transformation in Higher Education}

Organizations, regardless of their business domain, struggle with the integration of digital technologies in their existing practices and processes. In the case of higher education institutions, the process of digital transformation becomes more complex due to a number of problematic trends such as declining enrollment, rise in operational costs, changing educational demands etc. Such trends increase the likeability of replacing existing IT infrastructure and applications with technologies that are better suited to higher education in the digital world. 
The concept of digital transformation transcends beyond the adoption of advanced digital technology only. In the case of higher education institutions, the transformation of the existing teaching and learning models is imperative for survival and sustaining the competitive position in the long term. Leaders in higher education have identified four main and consistent goals. These goals are to improve the students' learning environment, increase operational efficiency, increase computing power for cutting-edge research, and stimulate innovation in education. For higher education institutions, it is imperative to rethink their teaching and learning practices by integrating digital tools in their existing systems, ultimately enriching their traditional pedagogical approaches and education system through advanced education delivery tools [22]. However, up till now, in higher education, technology has been viewed as a means for incremental changes in terms of improvement in the existing learning approaches. Technology has been largely ignored as a means for disruptive and evolutionary changes [23]. Moreover, the digital transformation in higher education must also extend beyond the innovation driven by the instructor for improving pedagogical approaches. It must also incorporate digitization skills rather than just focusing on supporting the learning processes with technology [24].

In order to sustain a competitive position and maintain a reputation in the present times, higher education institutions employ all possible digital technologies and tools to ensure continuous improvement of their education delivery and ensure superior student experience. Investing in technology to become more digital native and using this technology to help engaging students, tracking them, and predicting their success will eventually lead to a better student journey. In addition, digital solutions of the student journey can be used to recruit and retain students as well as improve digital education delivery.

National Center for Education Statistics shows that in the period between 2010 to 2018, the non-administrative expenses of US-based public and private not-for-profit highereducation institutions, rose by 18 per cent. In this regard, investing in technology and streamline business processes through technology will help a great deal in reducing operating costs. Using cloud technologies will also help in reducing maintenance overheads. Moreover, as scientific research becomes more complex, a need arises to have more scalable secure computing power. Digitizing these computing powers and using remote, networked or cloud-based research tools is a necessity for higher education institutions.

It is also worth noting that in the present times, digital-native students are the major drivers for the evolution of education delivery. Students have started to consider the digital experience as an essential part of their college experience. In some cases, it might be an important factor in selecting their institution. Digital maturity will allow higher education institutions to become more agile and effective in providing an education that adapts to changing educational needs, responding to changing preferences and predict future disruptions.

\subsection{Need for Digital Transformation in Higher Education}

In the present times, the mission of the higher education institutions is to develop the employability skills of the students for a specific career, in order to equip them to survive in the labor market for the following 30 or 40 years. Educational institutes rarely devote time to educating students on how to learn. Things have changed in the recent decade since it is now uncommon for employees to work for the same business for their whole career [14]. As a result, higher education institutions are faced with the task of preparing students for continuous learning. Thus, higher education institutions need to focus on the development of the self-efficiency and adaptability skills of the students [25]. In this regard, digital transformation can help accomplish contextualization in learning. Such skills and competencies must be integrated into all modules and courses, as well as all learning settings. If we can do this, we can begin to transform education. This way we can get a general idea of what "critical thinking" or "abstract thinking" means-we build a model-and through contextualization, later There we create concrete visualizations of "critical thinking in a field" [26]. 
Higher educational institutes also need to make well-researched and oftentimes fast choices in order to simplify operations and better understand their consumers. As such, meaningful data must be used to understand and delineate the trends and patterns that in turn influence decisions that will have the greatest impact on the institution as a whole [12] Furthermore, utilizing all of the chances and potentialities provided by the richness of digital technologies accessible, as well as rethinking full business models and transforming the operations and practices throughout the value chain is certainly one of the most difficult endeavors. Such a problem is more of concern for the business organizations as they always compete in the market to establish and sustain a competitive position in the industry. However, it is also emerging as a serious concern for the higher educational institutes due to the rising competition between the universities for the finest students and researchers grows [27]. Legacy systems can incur considerable costs and put pressure on budgets [13]. There is also a greater demand for security than ever before as a result of attacks on higher educational institutes both online as well as on-campus. Legacy or manual forms and methods will not be able to solve these issues. More than ever, higher education establishments need to embrace the use of digital technology for their daily operations [28].

\subsection{Dimensions of Digital Transformation in Higher Educational Institutes}

The incorporation of digital technologies can be used to transform various dimensions of higher education. One of the dimensions in teaching and pedagogy. Bozhko et al. [29] have emphasized the need of using tools that meet current educational standards and techniques, particularly those based on technology. Bond et al. [30] also stressed that digital advancement in the context of education has been going beyond just technical changes, rather, it has impacted the curricular as well as organizational and structural as well. Digital educational tools are seen as providing new roles for the researchers, teachers and learners, generating more interactive, simulative and engaging methods for teaching and learning, and enhancing collaboration and engagement [31]. Another major dimension is curriculum and digital literacy in terms of the establishment of digital skills and curriculum modernization. In the present digital era, a new highly skilled workforce with technological skills and expertise in technology and contemporary knowledge is required [32]. Furthermore, Bond et al. [30] have asserted that technical, as well as instructional advice, is required from the standpoint of university professors to prepare the students for future employability. As a result, there is a need to modernize the curriculum to meet current educational standards and techniques, including discovering new ways to accelerate digital learning and expanding the use of information and communication technologies [29]. Digital transformation can also be applied to the dimension of infrastructure and administration. As [33] asserted that digital transformation of the administrative architecture can result in an agile and flexible architecture that can enable the management to quickly adapt to the emerging technologies and systems. Similarly, Faria and Henriqueta [27] contemplated that a number of higher educational institutes have incorporated digital technologies for the improvement of their current practices in terms of how they handle student data and curriculum and to innovate their management experiences while making data-driven proactive and informed decisions.

\subsection{Education-Specific Transformation Frameworks}

The development of a maturity model of digital transformation in educational organizations must be theoretically sound and rigorously tested [21]. It must also take into account the core business of these institutions which are teaching and learning, research, and community service. Various companies have attempted to build a framework that guides universities and higher education institutions towards digital transformation. These attempts outline some foundational steps in the right direction. These frameworks differ in terms of their rigorousness. Nonetheless, the frameworks can help especially in cases where there is no clear strategy for these institutions. 


\subsubsection{KPMG Framework}

KPMG developed a research-based consumer-centric enterprise-wide framework for the digital transformation of higher education institutions [34]. The KPMG framework is intended to assist the educational institutes in better positioning themselves to create higher value and returns by structuring and aligning different aspects of the education system in order to offer seamless, consumer-centric service and experience. KPMG calls this framework "a blueprint for digital transformation in universities". The framework has six organizational elements namely, customers, channels, enterprise strategy, core businesses practices, advanced data and analytics, and enabling business practices. Figure 1 shows the organizational elements of the framework.

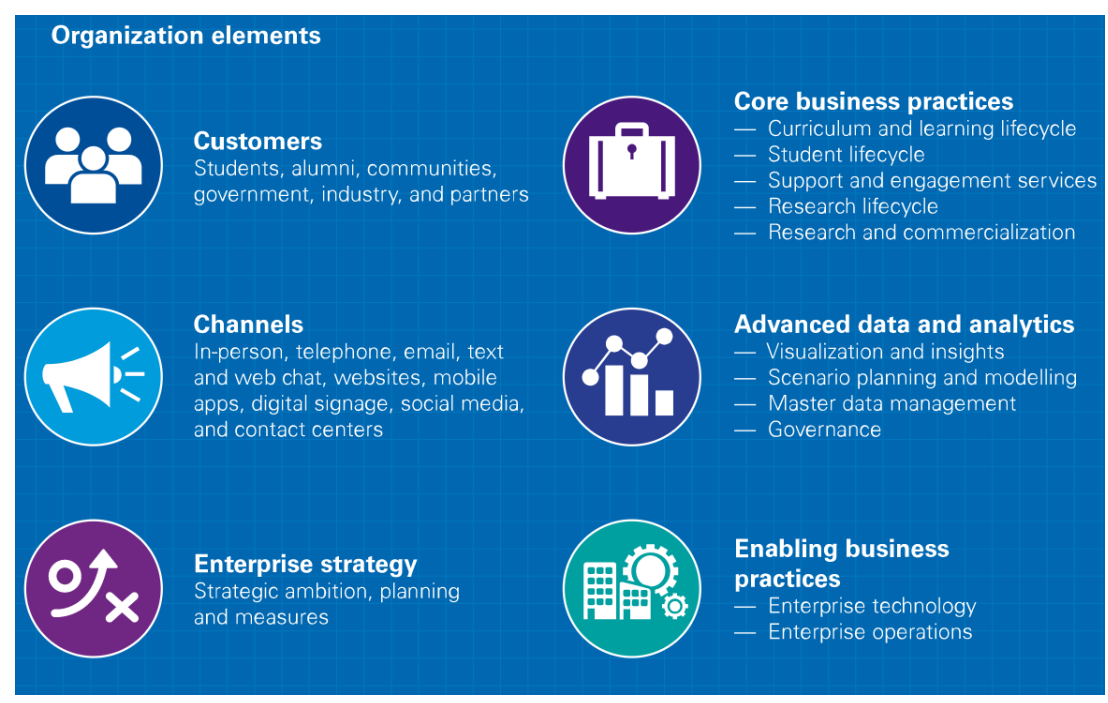

Figure 1. KPMG blueprint for digital transformation in universities.

"Customers" in this framework include existing and potential students, alumni students, educational communities, government and various partnering institutions. Channels entail all kinds of communication channels as mentioned in Figure 1. Enterprise strategy entails all the strategic objectives, goals and planning. Core business practices entail all the practices associated with curriculum, student experience, research and other academic areas. Visualizations and insights, scenario planning and modelling, data management and governance are all covered in data and analytics. Lastly, technology and operations are considered as enablers for business practices.

\subsubsection{Microsoft Framework}

Microsoft has presented a framework for the transformation of higher education [35]. The framework is proposed to provide practical guidance to assist the higher educational institutes in building a comprehensive digital transformation plan based on their vision and desired objectives. The framework is divided into four major dimensions: student achievement, teaching and learning, academic research, and a secure and connected campus. Figure 2 provides an overview of the framework.

Student success focuses on attracting students, meeting the educational needs of the students and building lifelong relationships with them. The teaching and learning dimension is focused on building a culture of continuous learning and improvement in education delivery. The academic research dimension focuses on empowering all researchers and providing them with all the necessary skills and competencies. The secure and connected campus dimension is concerned with a rethinking of the configuration, optimisation and management of the campus resources. 


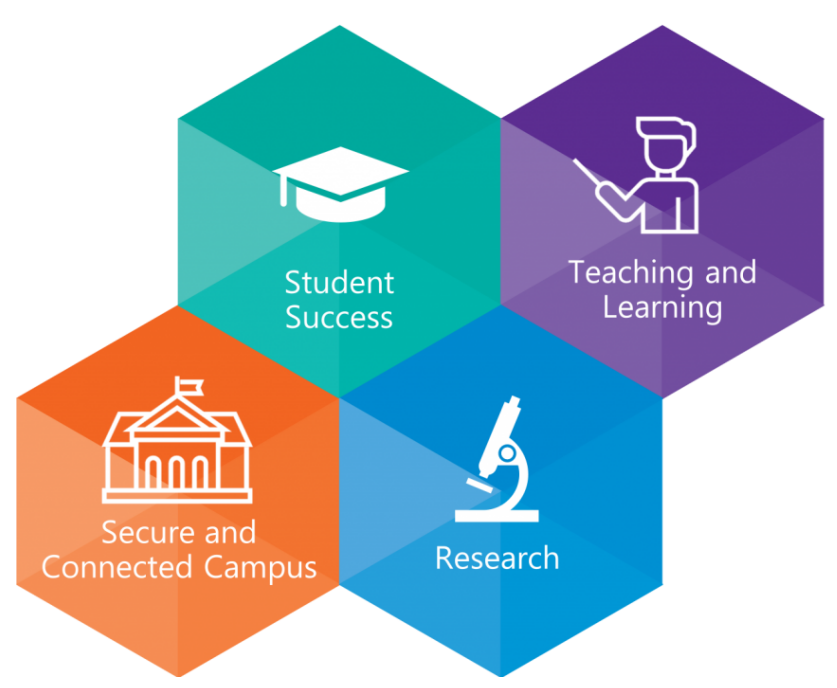

Figure 2. Microsoft Education Transformation Framework for Higher Education.

\subsubsection{Google Framework}

Google has its own education transformation framework [36]. Figure 3 provides an overview of the framework. Google has classified seven elements of transformation namely vision, learning, culture, technology, professional development, funding and sustainability, and community engagement. As per this framework, the digital transformation in higher education delivery can also take place when there is a strong vision from the outset. When the higher education institute has a clear vision, it implies that the leadership and the larger community are working together toward common future goals. The framework also presents the idea that that the university leadership must foster an innovative culture and encourage people to take risks and learn from failures. Moreover, it must be noted that technology is not simply a facilitator of school transformation, but it is a vital element. Thus, the leadership must identify, test, and win the support of their team for the incorporation of the appropriate technology (tools and procedures) in pursuit of the institutions academic and administrative goals. After that, the administrators should develop a sustainable budget, identify a variety of financing sources, and look for savings and reallocation possibilities that are directly related to student goals.

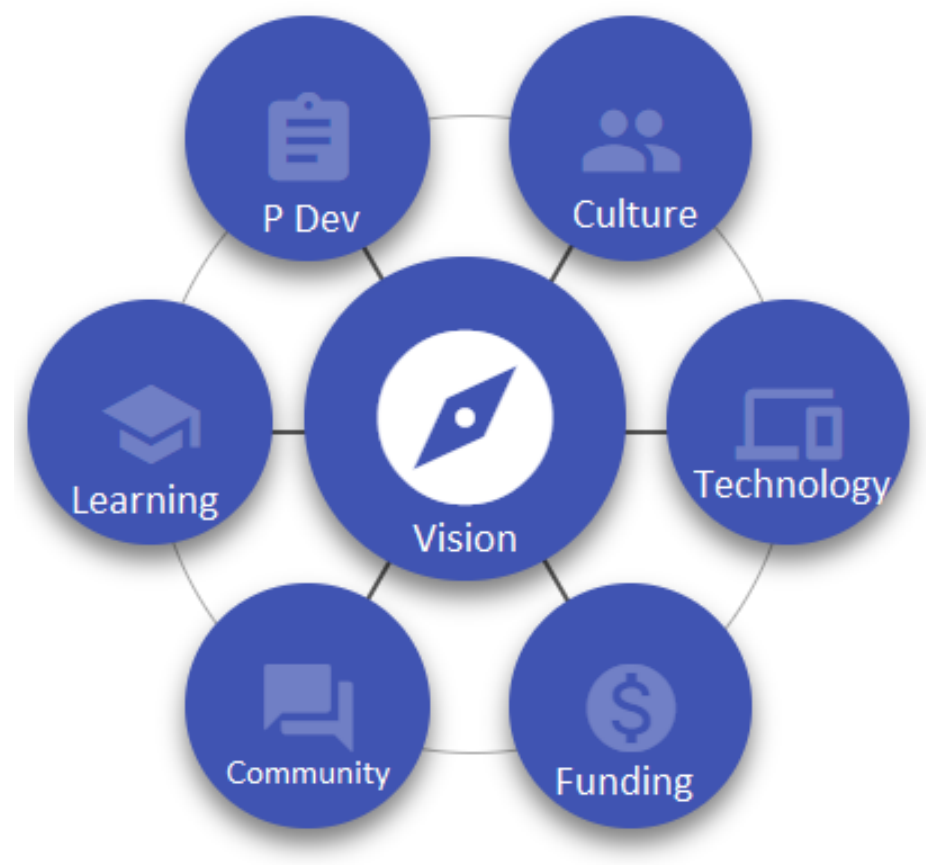

Figure 3. Google Education Transformation Framework. 
It must be noted that schools impact a varied community of parents, families, companies, government, organizations, and citizens. Thus, the leaders have to make certain that these stakeholders support the institute throughout its transformation. Lastly, the framework proposes that effective professional development and continuing coaching must be provided to the educators in order to help them use skills and techniques to meet the requirements of their students.

\subsection{The Existing Institutional Levels of Digital Transformation}

The outbreak of the COVID-19 global pandemic has pushed several industries to transform digitally to sustain their business. Consequently, education systems and higher educational institutes all around the world were also required to incorporate digital technologies in order to modify their education delivery system and adapt to the changing scenario. Many issues were raised concerning the provision of education to the students in terms of sustaining classroom learning, performing examinations, accommodating a large number of students etc. To keep operations running, several institutions joined up various online software for video conferencing and meeting such as Zoom and other software solutions [37]. As a result of this huge disruption, many institutions are establishing specialized digital strategies, yet a high number of institutes lack the vision, capacity, systems, expertise or even the commitment needed for the successful implementation of the digital tools. On average the status of digital transformation is still underdeveloped [27]. This aligns with the findings of Buvat et al. [38] that there is little discernible progress in developing skill and expertise in driving digital transformation and thus, institutes are struggling in this regard.

The existing institutional levels of digital transformation can be captured by assessing the digital maturity of the institutes. In this regard, Rodríguez-Abitia et al. [39] put forward a framework for assessing the digital maturity of higher educational institutes. The digital maturity of any educational institute can be assessed by observing its information technology infrastructure in terms of digital tools used in classrooms and labs as well as for administrative purposes. Moreover, it also needs to be assessed how the institutes have applied digital tools in teaching and learning. The authors found that the ability and progress of the higher educational institutes have been limited and impeded by various contextual constraints. Similarly, assessing the digital maturity of the higher educational institutions, Rodríguez-Abitia and Bribiesca-Correa [40] have asserted that the higher education institutions have been lagging behind other businesses and industries when it comes to embracing digital transformation. Due to market pressure, other industries have likely been compelled to develop quicker. Nevertheless, the educational industry is beginning to offer a variety of learning choices that may appeal to younger generations.

\section{Digital Transformation Challenges in Higher Education Institutions}

Research has revealed various challenges that act as obstacles in the digital transformation of higher education institutes [41-44]. The research done in this area is focused on different aspects and from different points of view. In this work, we are summarizing the main strategic high-level challenges that higher educations institutes usually face while adopting digital transformation. Figure 4 shows the major challenges pertinent to digital transformation in higher education institutions. 


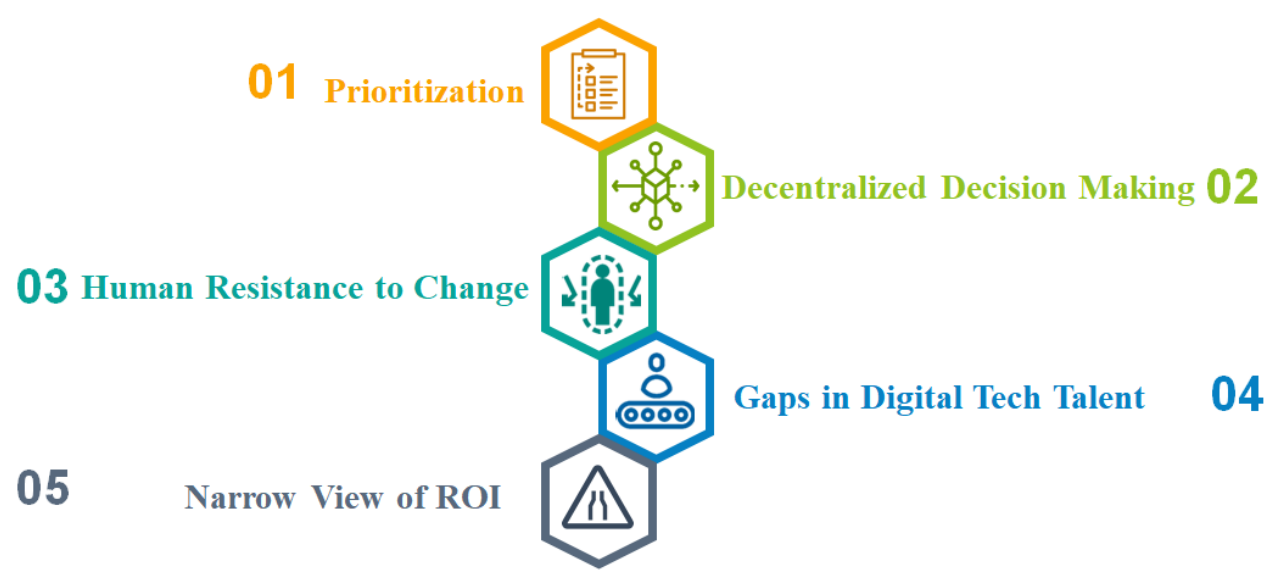

Figure 4. Challenges Pertinent to Digital Transformation in Higher Education Institutions.

These challenges can be summarized as follows:

- Prioritization: Universities tend to focus on urgent matters rather than important ones. They tend to prioritize immediate results and postpone critical investments in building capabilities that are time-consuming. It is asserted that planned digitization is not being done in a particularly novel fashion, nor with the necessary financial means to execute the plan, which further exacerbates this problem [40]. This issue can be dealt with through the development of a prioritization plan for digital investments a roadmap that can guide the systematic transformation of the organization in a sequential manner.

- Decentralized Decision Making: Decentralized decision making can cause delays in the implementation of large-scale decisions and projects. On the other hand, IT systems that are characterized by centralized control and decision making are more efficient. It is an important way to balance the scale and speed of coordinated decisionmaking. To ensure success, there is a need to build a dynamic ambidextrous organizing model for digital transformation to better balance separation and integration over time [45].

- Human Resistance to Change: It is a commonly agreed idea that the primary obstacle that higher educational institutes encounter in adapting to digital transformation is adjusting to new teaching methods and the learning settings and models. Thus, resistance to the adoption of digital transformation can be a major obstacle. Academic professionals are typically regarded to be some of the most secure occupations in the world. There is a good chance that change will be opposed if it threatens job security [40]. Successful organizations inspire their staff to advocate a vision of digital maturity. Small pilot projects can be used to give a clear picture of the potential change and eliminating uncertainly or the doubts of the faculty pertinent to job security. It is imperative to develop orientations for the educational professionals to guide them regarding the positive side of technology and reducing their job insecurity.

- Gaps in Digital Tech Talent: The low level of the digital literacy of the faculty is also a major challenge. In the context of the higher educational institutes, new teaching methods and learning tools and procedures such as the use of video conferencing, digital platforms, simulation-based learning and collaborative learning, must be adapted. Higher education systems are being pushed to adapt to global developments, which necessitates new teaching and learning paradigms and environment [46]. As the current students are digital natives, the lecturers must be more imaginative and inventive in their digital teaching abilities. Another major challenge to the successful implementation of digital technologies in the higher education system is the generational gap between the students that are considered as native to these digital technologies and the institutes' faculty that have to adapt and learn the use of the technologies. Thus, due to such generational disparities between students and technology adopting 
faculty, it is necessary to promote policies to enable both infrastructure and creative learning settings to address the changing punditry trends. In addition, there will be a substantial need for faculty training

- Narrow View of ROI: Lastly, it is found that higher education institutions usually make errors in calculating the business case and ROI for the investment. Business cases for basic digital skills should consider actions that are slowly evolving or difficult to quantify. Examples include saving faculty time and costs through more efficient operations and automation, as well as better enrollment, retention, and on-time graduation numbers that result from the improved student experience.

It is also found that the outbreak of the COVID-19 epidemic has pushed organizations around the world, to incorporate digital tools and technologies to adapt to the changing scenarios. The higher educational institutes have not been an exception to such transformation and thus, they have to transform their operations digitally in order to sustain the education delivery. The authors [47] observed that with the right tools and ingenuity, problems may be converted into opportunities. Thus, digital technologies may increase social connection, collaboration, interactions and engagement as with the incorporation of the new online platforms and programs, a higher number of instructors, teachers, experts and speakers can be accessed globally. However, models must be modified to satisfy the needs of online delivery. With such sudden adoption of digital technologies and mechanisms the need to encourage student engagement and interactions also rises, which can be easily lost or diminished when compared to a face-to-face situation, among other factors. Passing from a traditional venue to completely online distribution has not always made it easy to adjust the course to its newfound nature. To get a student to want to be interested and contribute, there is a need to establish a relationship, create communication linkages, and use information effectively [10].

\section{Conclusions}

The paper attempted to contextualize the digital transformation in the context of higher educational institutions. Conclusively, it is found that in the present era, similar to other industries and business organizations, the higher education institutions also need to transform digitally to remain relevant to the changing industry scenarios and trends. The digital transformation can be applied to several dimensions of the higher education system including teaching, pedagogy, learning and curriculum, infrastructure, and administrative and management. The paper also discussed the maturity models of the top firms to understand the relevant dimensions that can help in measuring the maturity of any higher education institution. The paper has also presented frameworks and models for the digital transformation of higher education institutions proposed by three leading firms; KPMG, Google, and Microsoft. It is also found that with such a high need for digital transformation, higher education institutes have been lagging behind the other industries and business organizations due to several challenges. Summarizing the key challenges that have been impeding the digital transformation of higher education institutions, it has been found that immediate focus and poor prioritization, decentralized decision making, internal resistance, digital literacy of the faculty fuelled by the generational gap of digital natives' students and faculty and narrow view of ROI are some of the major challenges in this context.

Funding: This research received no external funding.

Institutional Review Board Statement: Not applicable.

Informed Consent Statement: Not applicable.

Data Availability Statement: Not applicable.

Acknowledgments: The author would like to acknowledge the support of Prince Sultan University for paying the Article Processing Charges (APC) of this publication.

Conflicts of Interest: The author declares no conflict of interest. 


\section{References}

1. Heilig, L.; Schwarze, S.; Voss, S. An Analysis of Digital Transformation in the History and Future of Modern Ports. In Proceedings of the 50th Hawaii International Conference on System Sciences, Hilton Waikoloa Village, HI, USA, 4-7 January 2017.

2. Skog, D.A.; Wimelius, H.; Sandberg, J. Digital disruption. Bus. Inf. Syst. Eng. 2018, 60, 431-437. [CrossRef]

3. Morakanyane, R.; Grace, A.A.; O’Reilly, P. Conceptualizing Digital Transformation in Business Organizations: A Systematic Review of Literature. In Proceedings of the 30th Bled eConference, Bled, Slovenia, 18-21 June 2017; Volume 21.

4. Drechsler, K.; Gregory, R.; Wagner, H.T.; Tumbas, S. At the Crossroads between Digital Innovation and Digital Transformation. Commun. Assoc. Inf. Syst. 2020, 47, 23. [CrossRef]

5. Matt, C.; Hess, T.; Benlian, A. Digital transformation strategies. Bus. Inf. Syst. Eng. 2015, 57, 339-343. [CrossRef]

6. Rossmann, A. Digital maturity: Conceptualization and measurement model. In Bridging the Internet of People, Data, and Things: 39th International Conference on Information Systems (ICIS 2018), San Francisco, CA, USA, 13-16 December 2018; Curran Associates Inc.: Red Hook, NY, USA, 2019; Volume 2, pp. 1633-1641.

7. Valdés, K.N.; Cerdá Suárez, L.M. An Institutional Perspective for Evaluating Digital Transformation in Higher Education: Insights from the Chilean Case. Sustainability 2021, 13, 9850. [CrossRef]

8. Eden, R.; Jones, A.B.; Casey, V.; Draheim, M. Digital transformation requires workforce transformation. MIS Q. Exec. 2019, 18, 4. [CrossRef]

9. Orellana, V.; Cevallos, Y.; Tello-Oquendo, L.; Inca, D.; Palacios, C.; Rentería, L. Quality evaluation processes and its impulse to digital transformation in ecuadorian universities. In Proceedings of the 2019 Sixth International Conference on eDemocracy \& eGovernment (ICEDEG), Quito, Ecuador, 24-26 April 2019; pp. 338-343.

10. Balyer, A.; Öz, Ö. Academicians' Views on Digital Transformation in Education. Int. Online J. Educ. Teach. $2018,5,809-830$.

11. Hess, T.; Matt, C.; Benlian, A.; Wiesböck, F. Options for formulating a digital transformation strategy. In Strategic Information Management; Routledge: London, UK, 2020; pp. 151-173.

12. Gobble, M.M. Digital strategy and digital transformation. Res.-Technol. Manag. 2018, 61, 66-71. [CrossRef]

13. Marks, A.; Al-Ali, M.; Rietsema, K. Learning management systems: A shift toward learning and academic analytics. Int. J. Emerg. Technol. Learn. 2016, 11, 77. [CrossRef]

14. Mahlow, C.; Hediger, A. Digital Transformation in Higher Education-Buzzword or Opportunity? eLearn Mag. 2019, $2019,13$. [CrossRef]

15. Keegan, D. The Future of Learning: From eLearning to mLearning; ERIC: Washington, DC, USA, 2002.

16. Johnson, R.D.; Brown, K.G. E-Learning; American Psychological Association: Washington, DC, USA, 2017.

17. Proença, D.; Borbinha, J. Information security management systems-A maturity model based on ISO/IEC 27001. In Proceedings of the International Conference on Business Information Systems, Berlin, Germany, 18-20 July 2018; pp. 102-114.

18. Ifenthaler, D.; Egloffstein, M. Development and implementation of a maturity model of digital transformation. TechTrends 2020, 64, 302-309. [CrossRef]

19. Chanias, S.; Hess, T. How digital are we? Maturity models for the assessment of a company's status in the digital transformation. In Management Report/Institut für Wirtschaftsinformatik und Neue Medien; Institute for Information Systems and New Media, Munich School of Management, LMU Munich: Munich, Germany, 2016; pp. 1-14.

20. Carvalho, J.V.; Pereira, R.H.; Rocha, Á. A comparative study on maturity models for information systems in higher education institutions. In Proceedings of the 2018 International Conference on Digital Science, Budva, Montenegro, 19-21 October 2018; pp. 150-158.

21. De Bruin, T.; Rosemann, M.; Freeze, R.; Kaulkarni, U. Understanding the main phases of developing a maturity assessment model. In Australasian Conference on Information Systems (ACIS); Australasian Chapter of the Association for Information Systems: Sydney, Australia, 2005; pp. 8-19.

22. Jackson, N.C. Managing for competency with innovation change in higher education: Examining the pitfalls and pivots of digital transformation. Bus. Horiz. 2019, 62, 761-772. [CrossRef]

23. Branch, J.W.; Burgos, D.; Serna, M.D.A.; Ortega, G.P. Digital Transformation in Higher Education Institutions: Between Myth and Reality. In Radical Solutions and eLearning; Springer: Berlin/Heidelberg, Germany, 2020; pp. 41-50.

24. Hildebrandt, C.K. Whose interest is educational technology serving? Who is included and who is excluded? In RIED. Revista Iberoamericana de Educación a Distancia; Asociación Iberoamericana de Educación Superior a Distancia: Madrid, Spain, 2019; Volume 22.

25. Chappell, C.; Gonczi, A.; Hager, P. Competency-based education. In Understanding Adult Education and Training; Routledge: London, UK, 2020.

26. Moreau, M.P.; Leathwood, C. Graduates' employment and the discourse of employability: A critical analysis. J. Educ. Work 2006, 19, 305-324. [CrossRef]

27. Faria, J.A.; Nóvoa, H. Digital transformation at the University of Porto. In Proceedings of the International Conference on Exploring Services Science, Rome, Italy, 24-26 May 2017; pp. 295-308.

28. Norton, A.; Shroff, S.; Edwards, N. Digital Transformation: An Enterprise Architecture Perspective; Publish Nation Limited: London, UK, 2020. 
29. Bozhko, Y.V.; Maksimkin, A.I.; Baryshev, G.K.; Voronin, A.I.; Kondratyeva, A.S. Digital transformation as the key to synthesis of educational and innovation process in the research university. In Proceedings of the International Conference on Digital Transformation and Global Society, St. Petersburg, Russia, 22-24 June 2016; pp. 386-391.

30. Bond, M.; Marín, V.I.; Dolch, C.; Bedenlier, S.; Zawacki-Richter, O. Digital transformation in German higher education: Student and teacher perceptions and usage of digital media. Int. J. Educ. Technol. High. Educ. 2018, 15, 1-20. [CrossRef]

31. Elena, F. Embedding digital teaching and learning practices in the modernization of higher education institutions. Int. Multidiscip. Sci. Geoconf. SGEM 2017, 17, 41-47.

32. Azarenko, N.Y.; Mikheenko, O.V.; Chepikova, E.M.; Kazakov, O.D. Formation of Innovative Mechanism of Staff Training in the Conditions of Digital Transformation of Economy. In Proceedings of the 2018 Conference on Quality Management, Transport and Information Security, Information Technologies, IT and MQ and IS, St. Petersburg, Russia, 24-28 September 2018; pp. 764-768.

33. Tay, H.L.; Low, S.W.K. Digitalization of learning resources in a HEI-A lean management perspective. Int. J. Product. Perform. Manag. 2017, 66, 680-694. [CrossRef]

34. KPMG. KPMG Connected Enterprise for Higher Education. Available online: https://tinyurl.com/yt3rbbam (accessed on 22 August 2020).

35. Microsoft. Microsoft Education Transformation Framework for Higher Education. Available online: https://tinyurl.com/y5tskf49 (accessed on 22 August 2020).

36. Google. Google Education Transformation Framework. Available online: https://tinyurl.com/edsabvmu (accessed on 22 August 2020).

37. Marks, A.; AL-Ali, M.; Atassi, R.; Abualkishik, A.Z.; Rezgui, Y. Digital transformation in higher education: A framework for maturity assessment. Int. J. Adv. Comput. Sci. Appl. 2020, 11, 504-513. [CrossRef]

38. Buvat, J.; Puttur, R.; Bonnet, D.; Slatter, M.; Westerman, G.; Crummenerl, G. Understanding Digital Mastery Today; Capgemini Digital Transformation Institute: Paris, France, 2018; Volume 80.

39. Rodríguez-Abitia, G.; Martínez-Pérez, S.; Ramirez-Montoya, M.S.; Lopez-Caudana, E. Digital Gap in Universities and Challenges for Quality Education: A Diagnostic Study in Mexico and Spain. Sustainability 2020, 12, 9069. [CrossRef]

40. Rodríguez-Abitia, G.; Bribiesca-Correa, G. Assessing Digital Transformation in Universities. Future Internet 2021, 13, 52. [CrossRef]

41. Kutnjak, A.; Pihir, I. Challenges, Issues, Barriers and Problems in Digital Transformation-Systematic Literature Review. In Proceedings of the 11th International Doctoral Seminar (IDS 2019), Cologne, Germany, 12-16 March 2019; p. 7.

42. Aditya, B.R.; Ferdiana, R.; Kusumawardani, S.S. Barriers to digital transformation in higher education: An interpretive structural modeling approach. Int. J. Innov. Technol. Manag. 2021, 18, 2150024. [CrossRef]

43. Maltese, V. Digital transformation challenges for universities: Ensuring information consistency across digital services. Cat. Classif. Q. 2018, 56, 592-606. [CrossRef]

44. Rodrigues, L.S. Challenges of digital transformation in higher education institutions: A brief discussion. In Proceedings of the 30th IBIMA Conference, Madrid, Spain, 8-9 November 2017.

45. Smith, P.; Beretta, M. The gordian knot of practicing digital transformation: Coping with emergent paradoxes in ambidextrous organizing structures. J. Prod. Innov. Manag. 2021, 38, 166-191. [CrossRef]

46. Trifonov, V.; Shorokhova, N. University Digitalization-A Fashionable Trend or Strategic Factor of Regional Development? In The European Proceedings of Social \& Behavioural Sciences EpSBS; Future Academy: London, UK, 2019; pp. $1003-1013$.

47. Chen, Y.; Roldan, M. Digital innovation during COVID-19: Transforming challenges to opportunities. Commun. Assoc. Inf. Syst. 2021, 48, 3. [CrossRef] 